> the conflagration and gaseous fumes would have killed off or injured phytoplankton, along with birds, marine mammals and fish that were caught in the vicinity when the tanker ignited.

\section{UNCHARTED TERRITORY}

Moving beyond the fire, the impact of the accident becomes harder to discern. That's because the exact chemical composition of the condensate has not yet been made public, Steiner says, and because no one knows how much of the condensate dissolved into the water.

"The part I'm most worried about is the dissolved fraction," Steiner says. Toxic chemicals in the condensate could harm plankton, fish larvae and invertebrate larvae at fairly low concentrations at the sea surface, he says. Fish could suffer reproductive impairments as long as chemicals persist in the water, and birds and marine mammals might experience acute chemical exposure. "In a turbulent, offshore environment, it dilutes fairly quickly," he says. "But it's still toxic."

Because this type of spill is new, Portier says, scientists don't yet understand the ultimate consequences of acute exposure to condensate in the sea, or where it's breaking down and dispersing. "That's really where the science is missing," he says.

Researchers are also scrambling to assess where pollutants from the Sanchi could travel. Groups in both China and the United Kingdom have run ocean-circulation models to predict the oil's journey, and the models agree that much of the pollution is likely to end up in a powerful current known as the Kuroshio, which flows past southeastern Japan and out to the North Pacific. The European models suggest that chemicals from the Sanchi could reach the coast of Japan within a month. But the Chinese models indicate that they are unlikely to intrude on Japanese shores at all.

Katya Popova, a modeller with the National Oceanography Centre in Southampton, UK, isn't sure why the models disagree on this point. But, she says, the discrepancy points to the importance of forging international collaborations to increase confidence in model projections during emergencies: "This is something that the oil industry should organize and fund to improve preparedness."

Fangli Qiao, an oceanographer at China's State Oceanic Administration in Qingdao, says his group's models indicate that the pollution's probable path overlaps with Japanese sardine and anchovy fisheries. Still, Popova cautions that the models are imprecise indicators of potential harm to fisheries or coastlines.

"All we're saying is, if something is spilled here at this time, we can give you the most probable distribution," she says. "We don't know what type of oil or how much." Those are crucial details because condensate components could degrade or evaporate before reaching important fisheries or shores. "A monitoring programme is the most pressing need right now," Popova says, "to see where it goes and in what concentration."

Yet Steiner says that comprehensive environmental monitoring doesn't seem to have started. Official Chinese-government statements have included results from water-quality monitoring at the wreckage site, but none from the downstream currents that could be dispersing the pollution.

"Time is of the essence, particularly with a volatile substance like condensate," Steiner says. "They needed to immediately be doing plankton monitoring, and monitoring of fish, seabirds. I've seen no reports of any attempt to do that."

\section{CORRECTION}

The News Feature 'The dark side of light' (Nature 553, 268-270; 2018) erred in saying that differing levels of skyglow had no effect on algae. In fact, it was zooplankton that were analysed. It also cited the wrong journal in reference 9: it should have referred to Proc. R. Soc. $B$. 